\title{
Concepções de professores do ensino básico sobre a contribuição do PIBID na ação docente
}

\author{
Conceptions of school basic teachers on the contribution of PIBID \\ in the teaching action
}

\author{
Regiane Zanovello*1, Stéfani Dutra Mattana², Geovane Rafael Theisen³, \\ Terimar Ruoso Moresco ${ }^{4}$, Tânea Maria Bisognin Garlet ${ }^{5}$ \\ 1,2,3 Acadêmico do Curso de Ciências Biológicas UFSM - Palmeira das Missões, RS, Brasil. \\ 4,5 Docente do Curso de Ciências Biológicas UFSM - Palmeira das Missões, RS, Brasil
}

\begin{abstract}
Resumo
Este trabalho apresenta considerações de professores supervisores bolsistas do Programa Institucional de Bolsa de Iniciação à docência/PIBID frente às contribuições do projeto no exercício profissional da licenciatura. Para obter essas opiniões, os professores integrados ao PIBID responderam questões pautadas nas vantagens de estar inserido no programa e a importância dele para a sua formação continuada. As respostas do questionário trouxeram à tona diversas percepções dos educadores quanto à contribuição do projeto na sua formação, evidenciando que o PIBID colaborou para redirecionar o olhar docente a novas perspectivas, o que constituirá uma base fundamental para a consolidação de um novo perfil de educador.
\end{abstract}

Palavras-chave: PIBID; Docência; Educadores; Formação continuada.

\begin{abstract}
This work presents considerations of teachers supervising of Scholars Program Institutional Initiation Scholarship to teaching / PIBID forward to the contributions of the project in the exercise professional of graduation. For these views, two teachers answered some questions based in the advantages of being inserted in the program and the importance it for their continuing formation. The responses of the questions of the survey brought to light various perceptions of educators regarding the contribution of the program in its formation showing that PIBID collaborated to redirect the teacher look to new perspectives the which will provide a fundamental basis for the consolidation of a new profile educator.
\end{abstract}

Keywords: PIBID; Teaching, Educators; Continuing formation.

* regiane.zanovello@yahoo.com

Recebido: 20/03/2014 Aceito: 20/03/2014 


\section{Introdução}

A A formação, como um caminho de diversas possibilidades, permite às pessoas constituir relações que as levam a compreender continuamente seus próprios conhecimentos e os dos outros e associar tudo isso com suas trajetórias de experiências pessoais (ALVARADO-PRADA et al., 2010).

Nesse processo, o Programa Institucional de Bolsa de Iniciação à Docência/PIBID é um forte aliado no incentivo à formação de futuros docentes que buscam por meio do projeto, inovar suas práticas pedagógicas e obter a percepção prévia de como é o processo educativo antes de sua formação.

Diante disso, o PIBID passa a constituir uma iniciativa para o aperfeiçoamento e valorização da formação de professores na educação básica, pois concede bolsas a alunos de cursos de licenciatura e professores da educação básica e promove a integração entre o ambiente acadêmico e as instituições escolares da rede pública de ensino.

Buscando-se assim, verificar a contribuição do PIBID na formação continuada de dois professores da rede básica de ensino do município de Palmeira das Missões aplicou-se um questionário com perguntas relacionadas à ação docente e concepções desses educadores sobre as vantagens de estarem inseridos no programa.

\section{Material e métodos}

Bolsistas do PIBID Ciências Biológicas da Universidade Federal de Santa Maria realizaram, no período de outubro de 2011 a outubro de 2013, várias atividades inovadoras relacionadas ao projeto em duas escolas da rede estadual de ensino do município. No decorrer desses dois anos, acadêmicos bolsistas do programa juntamente com dois professores supervisores - um em cada instituição, direcionaram o ensino de Ciências a um perfil diferenciado e experimental. Para isso, foram realizadas atividades como oficinas, palestras, seminários; feira de Ciências; além da confecção de jogos didáticos, da promoção de reuniões/encontros pedagógicos e viagens de estudos, a fim de contribuir na iniciação docente de dez pibidianos e na formação continuada de dois professores do ensino básico.

Com o intuito de aferir a contribuição de todas essas modalidades didáticas na formação dos bolsistas, essa pesquisa teve como procedimento metodológico a elaboração e aplicação de questionário relacionado quanto a: atuação, vantagens e importância de estar inserido no projeto para consolidar propostas inovadoras ao ensino.

O instrumento investigativo utilizado para a coleta de dados foi composto de cinco questões abertas e consistiu nas seguintes perguntas:
Quais as vantagens que o PIBID proporciona em sua ação docente?

Qual sua visão sobre metodologias diferenciadas no processo de ensino-aprendizagem?

Em seus conteúdos, você costuma trabalhar os temas transversais propostos pelos PCNS? Que tipo de dificuldades você encontra para trabalhar esses assuntos?

Das atividades realizadas no PIBID, qual você achou mais interessante? Justifique.

Como os bolsistas PIBID podem ser inseridos no ambiente escolar para uma melhor aquisição/troca de experiências?

O processo de análise e sistematização das informações do questionário seguiu a metodologia proposta por Bardin (1979) e Minayo (2000), buscando-se traçar um panorama que verificasse se o PIBID teve resultado significativo na ação profissional dos professores supervisores.

\section{Resultados e Discussão}

O Programa Institucional de Bolsa de Iniciação à Docência (PIBID) foi criado com apoio da Coordenação de Aperfeiçoamento de Pessoal no Nível Superior (Capes), para incentivar a formação de novos educadores por meio de metodologias e didáticas diferentes ao ensino na educação básica em todo o País, ao mesmo tempo em que auxilia os atuais profissionais a desenvolverem atividades que diversifiquem o processo de ensino-aprendizagem (SILVA et al., 2012).

A formação de professores e a legislação educacional, especialmente a LDB 9.394/96, situam a formação de professores em duas modalidades principais: a inicial e a continuada. A formação inicial caracteriza-se por se dar no formato de cursos superiores realizados em Universidades, Institutos Superiores de Ensino ou cursos organizados pela Educação à Distância. Já, a formação continuada pode ser organizada e implementada pelas Secretarias de Ensino, através de um grupo de funcionários específicos ou pelas regionais pedagógicas que acompanham a escola (DE OLIVEIRA, 2008).

Para isso Lima (2001, p. 11) ressalta:

A formação contínua estaria, assim, a serviço da reflexão e da produção de um conhecimento sistematizado, capaz de oferecer a fundamentação teórica necessária para a articulação com a prática e a crítica criativa do professor em relação ao aluno, à escola e à sociedade. Estaria ainda ajudando a pensar a profissão, a profissionalização, o profissionalismo e o desenvolvimento profissional do professor. 
Diante dessas considerações, ao se questionar os supervisores sobre as vantagens que o PIBID proporciona na ação docente verificou-se que os professores relacionaram suas respostas ao fato de se reintegrarem ao ambiente universitário.

"a maior vantagem é a inserção no meio acadêmico, pois após a conclusão do curso o professor fica detento na escola." [SIC]

A universidade tem efeito transformador na sociedade, de modo, a desenvolver mentes criativas para resolver os problemas do futuro da sociedade e da humanidade (SEFIDVASH, 1994). Conforme argumenta um dos professores bolsistas do PIBID "a universidade é uma porta para novas ideias". Com isso, a integração entre universidade e escola, é sem dúvida, um fator importante não somente para os licenciandos, mas também para a formação continuada desses educadores já atuantes.

Outro fator a ser considerado, é que o movimento de interação permite que o bolsista compartilhe experiências de ambas as partes envolvidas no processo formativo e, desse modo, pode estabelecer uma rede de relações, conhecimentos e aprendizado não com o objetivo de copiar e criticar, mas no sentido de compreender a realidade e ultrapassá-la (PIMENTA \& LIMA, 2004).

Assim, pode-se dizer que o saber universitário e a prática escolar possibilitam "a construção de pontes entre teoria e prática" (MIZUKAMI, 2005, p. 10). Na consolidação dessa proposta o PIBID também é atuante, pois segundo a visão de outro docente:

"é um projeto muito importante que proporciona uma nova maneira de integração entre escola/universidade" [SIC]

Essa redescoberta do mundo acadêmico evidencia que a inserção no programa tem reestabelecido uma relação que, para a maioria deles, estava bastante distante.

Entendendo que o desenvolvimento humano acontece no processo de aprendizagem e vice-versa, a formação é também um processo de desenvolvimento humano e, portanto, profissional (ALVARADO-PRADA et al. 2010). Esses mesmos autores consideram que no caso dos docentes, a base profissional se desenvolve principalmente nos contextos de seu trabalho exercido na instituição escolar onde criam relações alicerçadas em estruturas complexas que as sustentam ou permitem sua alteração.

A escola, nesse caso, não serve apenas para difundir ideias dos educadores já formados. A inserção dos futuros professores no ambiente escolar segundo Maldaner (2006) faz com que eles se sintam valorizados em sua profissão e compromissados com as orientações curriculares produzidas, uma vez que, passam a participar do processo de implementação de melhorias.

Essas melhorias na qual Maldaner se refere podem ser alcançadas e efetivadas com ferramentas e propostas inovadoras, pois os supervisores afirmam: "o novo ensino exige do professor várias metodologias a serem aplicadas, assim precisamos nos adaptar às mudanças dos "alunos tecnológicos", mas nunca esquecer a importância de saber usar no momento certo" [SIC]

"acredito que para uma educação de qualidade ser prazerosa é preciso de metodologias diferenciadas que estimulem e atraiam a vontade de querer aprender." [SIC]

"Sabemos que grande parte de nossos alunos sentem-se obrigados a estar na escola. Cabe a nós educadores, realizar nosso trabalho da melhor forma possível, utilizando-se de recursos e metodologias de ensino variadas para atender as diferenças em nossas salas de aula" [SIC]

É na concretização dessas ideias que o PIBID pode ser um importante aliado, pois suas propostas consistem também na remodelação de novas estratégias de ensino. Na percepção dos professores entrevistados, com o programa:

"o docente tem a oportunidade de buscar algo novo a ser aplicado no meio escolar, mas com um conhecimento prévio a ser trabalhado" [SIC]

"temos a oportunidade de rever conceitos da área das ciências, novas metodologias, práticas, que irão auxiliar na minha docência" [SIC]

"foi proporcionado a leitura e discussão de artigos relacionados à área da educação a qual é de fundamental importância para nossa formação pedagógica. Essas leituras me auxiliaram na análise de minha prática, bem como o meu bem fazer em sala de aula" [SIC]

No âmbito da educação básica, Silva et al.,(2013) argumentam que o educador exerce um papel fundamental na inserção de novas estratégias metodológicas no sentido de estimular a participação dos educandos no processo de ensino e aprendizagem.

A formação continuada de professores, nesse contexto, passa a ser encarada conforme Alvorada-Prada et al., (2010) como uma ferramenta que auxilia os educadores no processo de ensino-aprendizagem de seus alunos, na busca de novos conhecimentos teórico-metodológicos para o desenvolvimento profissional e a transformação de suas práticas pedagógicas. Na mesma direção, a escola, como instituição educacional e como espaço de formação continuada dos professores, precisa proporcionar recursos e tempo para que os educadores possam compreender a realidade da instituição na qual estão inseridos, analisá-la e, consequentemente, transformá-la, afinal:

\footnotetext{
"nem todos os alunos estão inseridos no mundo virtual, precisamos fornecer diversos caminhos para que o aluno aprenda o conteúdo" [SIC]
} 
"um ponto importante é conhecer a metodologia que o professor aplica nas suas aulas, assim os bolsistas podem e devem trazer algo novo para ser aplicado no ensino" [SIC]

Diante disso, as aulas planejadas e executadas com um olhar diferenciado e contextualizado, também podem ser contribuintes importantes para o processo da construção do saber. Algumas formas de propiciar atuações diferenciadas foram expressas pelos professores ao argumentarem que para o ensino de Ciências é necessário:

"transformar as aulas em algo atrativo para o aluno" [SIC]

"confeccionar jogos didáticos, com os próprios alunos, usar multimídia, o laboratório de Ciências e informática." [SIC]

As atividades práticas constituem fatores essenciais para o desenvolvimento cognitivo, logo sua aplicação no ambiente de ensino estimula a criatividade e contribui para a contextualização dos saberes (ZANOVELLO et al., 2013). Na mesma direção Silva et al. (2013) sugerem que são inúmeras as atividades que podem ser trabalhadas de acordo com novos olhares e novas perspectivas, pois o desenvolvimento dessas práticas diferenciadas se insere no ensino como proposta metodológica dinâmica com um caráter extremamente atrativo. Logo, é necessário segundo a concepção dos professores:

"[...] fazer com que o aluno trabalhe o mundo ao seu redor, mas com diferentes visões." [SIC]

Para contextualizar o aluno ao meio no qual está inserido, o educador precisa estimular os seus alunos a exercitar o olhar espacial no qual os aspectos essenciais são a observação, reflexão e análise dos lugares, incitando a leitura da paisagem por meio de uma visão ampliada e crítica (SILVA et al., 2013). Em consonância, Rodrigues (2002) sugere que a sala de aula, como espaço social, representa um campo plural e permanente de construção de saberes a partir de interações e representações que constituem as estruturas de produção de saberes. Instrumentos sugestivos podem nesse caso ser eficazes na prática docente diante da abordagem de conteúdos que, muitas vezes, são de difícil compreensão pelos estudantes. Deste modo cabe ao professor criar possibilidades de produzir materiais didáticos a partir da busca conceitual desse instrumento pedagógico (MATTANA et al., 2012) .

O ensino de Ciências Naturais, relativamente recente na escola fundamental, tem sido praticado conforme destacam os PCNs de acordo com diferentes propostas educacionais, que se sucedem ao longo das décadas como elaborações teóricas e que, de diversas maneiras, se expressam nas salas de aula. Muitas práticas, ainda hoje, são baseadas na mera transmissão de informações, tendo como recurso exclusivo o livro didático e sua transcrição na lousa; outras já incorporam avanços, produzidos nas últimas décadas, sobre o processo de ensino e aprendizagem em geral e sobre o ensino de Ciências em particular (PCN, 1997).

No entanto, para que esses temas sejam trabalhados adequadamente é necessário que os tópicos estejam inter-relacionados à vivência contemporânea dos estudantes e estabeleçam uma postura reflexiva da estrutura curricular no ensino de Ciências.

Assim, ao expressarem suas opiniões sobre a abordagem dos temas transversais no ensino de Ciências um dos professores supervisores enfatizou: "trabalho esses assuntos; nas reuniões pedagógicas são escolhidos
alguns temas transversais para se trabalhar durante o ano." [SIC]

Em contrapartida, o outro docente argumenta:

"não costumo trabalhar, fica mais no papel. Às vezes é realizado um projeto com dois ou três professores contemplando um tema." [SIC]

Essas dificuldades encontradas em trabalhar essas propostas dos parâmetros curriculares na pedagogia de ensino dos professores, são justificadas principalmente pela:

"falta de tempo entre os professores para discutir e planejar um trabalho interdisciplinar." [SIC]

Embora a indisponibilidade de tempo possa anteparar o desenvolvimento dos temas transversais propostos pelos PCNs para um dos docentes, o outro, no entanto afirma:

"não tenho dificuldades já que na área de Ciências fica fácil estabelecer relações entre o conteúdo programático e os temas transversais." [SIC]

A ideia dos temas transversais proposta pelo MEC, é mais uma tentativa de articulação entre as diferentes atividades escolares e a sociedade (DE MACEDO, 1998). É nessa articulação que o PIBID pode ser um importante intermediador ao se considerar as diversas atividades integrativas, que foram realizadas desde o início do subprojeto. A opinião de que "todas as atividades me trouxeram aprendizado" foi evidenciada por um dos professores quando questionados sobre a atividade mais interessante proporcionada pelo PIBID. Outra pedagogia considerada interessante na socialização do aprendizado foi a discussão dos artigos nos encontros e a realização de uma feira de Ciências promovida pelo Projeto nas escolas contempladas pelo programa.

"todas as atividades foram interessantes, mas a que vou destacar
é a feira de Ciências por ter envolvido um grande número de
alunos, pais, professores, coordenação e direção da escola." [SIC] 


\section{Com relação à feira:}

"essa atividade comprovou que nossos alunos são maravilhosos quando estimulados ao novo e que a educação pode sim ser significativa" [SIC]

Já em relação às discussões de artigos:

"podemos ver a diferença que há entre os textos escritos e a realidade que está inserida nas escolas de educação básica" [SIC]

"o mais interessante nessa atividade foram as diversas visões e opiniões citadas pelos professores do ensino superior, professores do ensino básico e acadêmicos" [SIC]

“esses momentos enriquecem o trabalho de todos que estão no ambiente, pois as opiniões são lançadas por pessoas que estão em diferentes fases de formação." [SIC]

É nessa perspectiva, que os docentes da educação básica podem contribuir para a formação de futuros professores, por meio do compartilhamento de suas vivências e dos conhecimentos adquiridos na prática docente.

Logo, a aprendizagem da leitura tem que estar vinculada em práticas formativas onde a compreensão da linguagem esteja indissociavelmente atrelada à realidade social dos estudantes. A leitura é um dos meios de o indivíduo manter-se informado e aprender em todas as esferas do interesse humano. Assim Solé (1998) destaca:

A palavra escrita tem características que a distinguem de outros meios de informação audiovisual, por sua flexibilidade e capacidade de transmissão de grande quantidade de informações, de estimular a imaginação e, especialmente, de ser controlada pelo leitor, sujeito ativo que processa o texto por meio de suas habilidades de raciocínio, conhecimentos, experiências e esquemas prévios.

A opinião supramencionada pode nos direcionar ao conceito de que a troca de informações entre os futuros docentes e os professores já atuantes condiciona trocas de experiências fundamentais que redirecionam o perfil educador a diversos pontos de vista, enriquecendo o espaço para o diálogo e consequente difusão de novas informações.

Para isso, Nascimento (1996) considera a formação continuada de professores na escola como uma necessidade. Constata que a maioria dos profissionais da escola tem uma formação inicial precária, que não os habilita a lidarem com os desafios e com os aspectos dificultadores, apresentados pela prática. Assim, há uma crescente demanda apontada para a formação continuada, realizada na própria escola, no sentido dela se configurar como suporte para a construção de conhecimentos do professor e para inovação das práticas escolares, no cotidiano de sua própria ação pedagógica. Sinaliza, ainda, que essa formação é importante para a descoberta de saberes docentes que se constroem na ação coletiva, na troca entre os professores e destes com os pais e os alunos e no registro e sistematização da prática que deve se dar em diálogo permanente com a teoria.

Os profissionais da educação nesse caso necessitam de capacitações e formações que venham proporcionar uma nova dinâmica no cotidiano escolar, que possibilite aos docentes e discentes a interatividade com o conhecimento de forma objetiva e prazerosa, acompanhando as modificações dos paradigmas e o crescimento tecnológico (SILVA et al., 2012).

Entrelaçando esses pensamentos aos de Nascimento (1996) observamos:

A formação continuada de professores precisa estar,preferencialmente, voltada para a escola, por ser este o espaço de contato, de convivência e de comunicação entre os profissionais que ali trabalham. [...] a escola é o contexto do trabalho do professor, ou seja, é nesse espaço que estão presentes os problemas reais do cotidiano escolar, as dúvidas pedagógicas dos professores e, certamente, as possibilidades de encontrar soluções (p. 144, 145).

Com base nesses aspectos que condicionam a formação, um professor supervisor evidencia:

"o educador deve estar aberto para situações novas e com o PIBID tive a oportunidade de participar de várias atividades como passeios, viagem de estudos, leitura de artigos, confecção de materiais, oficinas e contato com pessoas diferentes do meu dia-a-dia, as quais tivemos que aprender a respeitar as diferenças e conviver em harmonia." [SIC]

Nesse mesmo enfoque Alvarado-Prada et al. (2010) destacam que formar-se é um processo de toda a vida; enquanto seres humanos, temos a possibilidade de aprender e, portanto, nos humanizamos permanentemente, mediante as relações e interações que acontecem nos diversos ambientes culturais nos quais temos relações. Uma maneira de possibilitar esse elo em diferentes espaços formativos é, segundo a visão dos professores entrevistados, inserir os bolsistas no ambiente escolar.

"é preciso que os bolsistas estejam presentes na escola participando das atividades promovidas, das reuniões pedagógicas, na elaboração de atividades docentes conviver com os alunos para que tenham realmente a prática aliada à teoria" [SIC]

"é preciso que os acadêmicos se sintam parte da escola, que tenham vontade de estar nela, que gostem do ambiente escolar, das atividades escolares, tenham comprometimento, responsabilidade, amor na tarefa de educar" [SIC]

Além disso, segundo as percepções dos supervisores, os bolsistas devem: 
"ter a disponibilidade de tempo de acordo com a realidade da escola." [SIC]

“muitas escolas não proporcionam a interação dos bolsistas, cabe aí ao supervisor da escola fazer a ponte entre essas questões." [SIC]

Ratificando a fala dos supervisores Moretti et al. (2013) evidenciam que as ações do professor supervisor no PIBID não apenas revelam sua função de mediador na iniciação docente do estudante de licenciatura, como oportunizam, para o próprio supervisor, reflexões sobre sua prática docente na vivência das trocas de conhecimentos que se estabelecem entre ele, os bolsistas e os professores da universidade.

Outra perspectiva expressa pelos professores entrevistados é o fato do pibidiano não ser considerado um estagiário. Para isso os supervisores destacam:

"os bolsistas estão na escola para conhecer e interagir de um modo diferente do aluno estagiário." [SIC]

Argumentam também que compete aos bolsistas:

"buscar metodologias diferenciadas e propor para o professor a aplicação, isto é, levar para o meio escolar algo que venha chamar a atenção do aluno para a disciplina a ser trabalhada." [SIC]

Segundo Corrêa (2013), o PIBID tem um papel fundamental diante dessa situação de formação prévia. A presença dos bolsistas acadêmicos na escola possibilita nesse caso, que os bolsistas juntamente com os professores regentes, planejem e adotem múltiplas metodologias para atender às diferenças presentes na sala de aula. Dessa forma, o programa poderá promover a inserção dos estudantes no contexto das escolas públicas, desde o início da formação acadêmica para que possam desenvolver atividades didático-pedagógicas e conciliar mais diretamente o contexto dos alunos, com diagnóstico da realidade e dados sobre os conhecimentos prévios dos educandos das escolas. Esses fatores se mostram necessários para o planejamento das ações de transposição dos conhecimentos científicos adequados aos conteúdos escolares.

\section{Conclusões}

A formação de professores continua sendo uma das principais dificuldades na educação. Entretanto, existem maneiras de intervir para condicionar uma melhor formação de muitos educadores e, nesse caso, o PIBID pode atuar como um forte instrumento de apoio à educação básica. Isso pode ser confirmado na análise das respostas do questionário que evidenciou diversas percepções dos professores supervisores do projeto, quanto à contribuição do programa na formação docente. Os docentes puderam identificar aspectos relevantes do
PIBID e que segundo eles vieram a facilitar sua atuação profissional e implementação de novas metodologias no ensino de Ciências.

O programa apresentou importante significado na formação continuada desses dois professores do ensino básico e possibilitou um olhar inovador e diferenciado de suas praticas pedagógicas, o que constituirá uma base fundamental na consolidação de um novo perfil de educador.

Sabendo da importância dos cursos de licenciatura na formação de novos profissionais faz-se necessário, portanto, investir na formação e desenvolvimento docente para consolidar os saberes construídos pelos professores ao longo de sua experiência no exercício da profissão. Para tanto, a proposta do PIBID é adequada, pois, além de promover o aperfeiçoamento da formação de professores e a melhoria de qualidade da educação básica, ele busca desenvolver esta "qualidade na educação" mediante a parceria universidade - escola.

\section{Agradecimentos}

Os autores agradecem à Coordenação de Aperfeiçoamento de Pessoal de Nível Superior (CAPES) pela concessão de Bolsa no Programa Institucional de Bolsa de Iniciação à Docência/PIBID. Agradecem também aos professores supervisores do subprojeto PIBID Ciências Biológicas UFSM Campus Palmeira das Missões pela participação nas respostas do questionário.

\section{Referências}

ALVARADO-PRADA, L. E.; FREITAS, T. C.; FREITAS, C. A. Formação continuada de professores: alguns conceitos, interesses, necessidades e propostas.

Revista Diálogo Educação, Curitiba, v. 10, n. 30, p. 367-387,2010.

BARDIN, L. Análise de conteúdo. Lisboa: Edições 70, 1979.

BRASIL. Secretaria de Educação Fundamental. Parâmetros Curriculares Nacionais: Matemática. Brasília: MEC/SEF, 1997.

\section{CORREAA, K.R.C \& BATISTA,L.A. PIBID em} prática: relato de experiências sob o olhar das supervisoras na escola. Anais V Simpósio sobre formação de professores. Campus universitário de Tubarão, 2013.

DE OLIVEIRA, M.A.V. Formação continuada na escola pública e suas relações com a organização do trabalho docente. Faculdade de Educação UFMG. Belo Horizonte, 2008. 
LIMA, Maria do Socorro Lucena. A formação contínua do professor nos caminhos e descaminhos do desenvolvimento profissional. Doutoramento em Educação- USP, São Paulo, 2001.

MALDANER, O.A. A formação inicial continuada de professores de química: professores/pesquisadores: Ed.Unijui, 2006.

MATTANA, S.D.; CARVALHO, M.S.;JOHAN, C.S.; ZANOVELLO, R.; PERIPOLLI, S.Z. Importância do trabalho com material didático para uma aprendizagem significativa. Anais II Seminário Internacional de Educação em Ciências. Rio Grande, 2012.

MINAYO, M. C. de S. O desafio do conhecimento: pesquisa qualitativa em saúde. 7. ed. São Paulo: Hucitec, 2000.

MIZUKAMI, Maria da Graça Nicoletti. Aprendizagem da docência: professores formadores. Revista E-Curriculum, São Paulo, 2005.

MORETTI, V.D.; SILVESTRE, M.A.; LLATA, D.S.G.; ZEFERINO, L.C. A Aprendizagem da docência em matemática: o professor supervisor do PIBID em atividade de ensino. Anais do XI Encontro Nacional de Educação Matemática. XI Encontro Nacional de Educação Matemática. Curitiba Paraná, 2013.

NASCIMENTO, M. das G. C. de A. A escola como espaço de formação continuada de professores: análise de uma experiência. Dissertação (Mestrado em educação) Faculdade de Educação, Universidade Federal de Minas Gerais, Belo Horizonte, 1996.

PIMENTA, S.G. \& LIMA, M.S.L. Estágio e docência. São Paulo: Cortez, 2004.

RODRIGUES, J.R.T. A sala de aula e o processo de construção do conhecimento. Disponível em:< http://www.ufpi.br/subsiteFiles/ppged/arquivos/ files/eventos/evento2002/GT.2/GT2_14_2002. pdf $>$ Acesso em 15 out.2013.

SEFIDVASH, FARHANG. O papel da universidade na transformação da sociedade. II congresso de educação para integração da América latinaIntegração e cidadania, Maringa-PR,1994.

SILVA, L. G. F.; LOPES, R.L.S.U.; DA SILVA, M.F.; JÚNIOR, W.T. Formação de professores de Física: experiência do Pibid-Física da Universidade Federal de Rondônia. Revista Brasileira de Pós
Graduação, Brasília, 2012.

SILVA, P. A. S.; DOS SANTOS, F. F. S.; MENEZES, S.S.M. Contribuições do programa institucional de bolsa de iniciação a docência-(PIBID) no ensino de geografia: relato de experiências na escola estadual Olavo Bilac. Reencuentro de Saberes Territoliales Latinoamericanos. Peru, 2013.

SOLÉ, I. Estratégias de leitura. Porto Alegre: Artmed, 1998.

TARDIF, M. Saberes docentes e formação profissional. Petrópolis, RJ: Vozes, 2010.

ZANOVELLO, R.; MATTANA, S. D.; OLIVEIRA, R. P.; JOHAN, C. S.; CARVALHO, M. S.; MORESCO, T. R. GARLET, T. M. B. O jogo didático na contextualização dos saberes: instrumento de ensino útil para a mediação da aprendizagem. Anais XV Seminário Internacional de Educação no Mercosul. UNICRUZ, 2013. 